\title{
Chips Off the Old Blockchain
}

\section{WILL BITCOIN AND BLOCKCHAIN TECHNOLOGY BE THE OPERATING SYSTEM OF THE FUTURE?}

By Sherree DeCovny

Bitcoin was created in 2009 to serve as a virtual currency system outside the controls of the government or a central bank. Since then, both the cryptocurrency and the underlying blockchain technology have attracted significant attention worldwide. Several companies already accept payment for goods and services in Bitcoin, with the attraction being low processing costs and ease of use in cross-border transactions.

Currently, Bitcoin's global market capitalization is less

An expansive range of products and services are being built around Bitcoin, blockchain, and distributed ledger technologies.

Financial firms are looking at ways to leverage blockchain technology for the purpose of increasing efficiency and to incorporate it into portfolios.

Some argue that structural flaws in the Bitcoin mining process have implications for broader adoption into mainstream finance. than $\$ 3.5$ billion, according to Ron Quaranta, CEO of Digital Currency Labs and chairman of the Wall Street Blockchain Alliance. Yet there is sufficient interest for firms to create an expansive range of products and services around it.

Some argue that the blockchain, an immutable record of title that describes the ownership of any type of asset, is more interesting than Bitcoin itself. Similar peer-to-peer technology approaches, known as distributed ledger systems, have emerged. These systems facilitate the movement of value and capital without going through an intermediary. Blockchain and distributed ledger technology could offer an entirely different way of engaging in commerce and could reinvent the way value and risk are shared between counterparties. There are potential applications in such areas as payments, trade finance, trading, clearing and settlement, physical property title transfers, and more.

"There is going to be disruption, and I suspect there are going to be roles and capabilities that will become antiquated," says Quaranta. "But that opens up an entirely new realm for business and for jobs."

\section{PROOF OF CONCEPT}

Overstock sees blockchain as the future for retail sales and a viable replacement for many types of transactions. In January 2014, Overstock became the first major online retailer to accept Bitcoin; by August of the same year, the company had committed to creating $t \varnothing$, a platform for exchanging cryptosecurities. Overstock is still awaiting full regulatory approval from the US SEC to commence operations using the platform. Once that happens, companies will be able to issue securities on the $t \varnothing$ platform, where they can be converted to a digital format and traded openly.

Meanwhile, Overstock decided to test the waters by issuing a bond on the Bitcoin blockchain. Overstock made available up to $\$ 25$ million in a debt offering. Patrick Byrne, Overstock's CEO, bought $\$ 500,000$ of the offering. In July 2015, Overstock lent money to First New York Managed Accounts to purchase $\$ 5$ million worth of bonds as a proof of concept.

If the t $\varnothing$ platform is approved, companies will be able to issue shares that will resemble cryptocurrency (although they will not be Bitcoin), and transactions will be completed using blockchain technology. Broker/dealers will be able to connect to $t \varnothing$ just like they do to any other alternative trading system and place orders through their usual order management system. The experience will be the same as transacting on any other exchange, except that these trades will settle immediately rather than three days later.

\section{RULES AND REGULATIONS}

Financial institutions originally were cautious in their approach toward Bitcoin because of the lack of a defined market structure and uncertainty about the legal/regulatory framework. But now the New York State Department of Financial Services (NYDFS) is issuing BitLicenses, which some believe will be a template for other jurisdictions.

The BitLicense stipulates certain governance and cybersecurity requirements for financial institutions, including exchanges. Financial services firms already have rigorous compliance programs in place, so it is not a huge leap for them to qualify.

The challenge with the BitLicense is that it has no bluesky provision, so companies have to deal with multiple regulators, notes John Betts, CEO of Noble Markets. Obtaining a BitLicense is an expensive, cumbersome process that excludes many firms, especially startups.

Investors may be deterred by the licensing process, which limits the capital pool and ultimately slows down innovation. Moreover, some companies will no longer do business with New York state residents, so New Yorkers are working around the regulations by doing business with firms in offshore jurisdictions. Ultimately, they lose any protections that they could have had if there was a lighter touch to regulation or a blue-sky approach.

A number of businesses have applied for the BitLicense, so it is not a complete barrier to entry. Moreover, the blockchain community has been in discussions with the NYDFS to address concerns.

\section{STEPPING UP}

In addition to the BitLicense, a few other developments 
have given financial institutions a green light to adopt a more public strategy. Among them are NYSE's investment in Coinbase and Noble Markets' partnership with NASDAQ.

Most major banks and broker/dealers have launched digital currency and blockchain technology initiatives. Some are focusing on uses of blockchain technology to replace inefficient, costly legacy database and storage systems. For example, JPMorgan Chase, Barclays, Goldman Sachs, Banco Bilbao Vizcaya Argentaria, Commonwealth Bank of Australia, Credit Suisse Group, State Street, Royal Bank of Scotland, and UBS are collaborating with R3 to develop standards and protocols for deploying blockchains in syndicated loans and repurchase agreements. Furthermore, Barclays in the UK has an accelerator program to incubate financial technology startups with the objective of importing innovative ideas into the banking world.

"The key is to understand why Bitcoin adds value and what kind of applications and services will be built around Bitcoin," says Gil Luria, a managing director at Wedbush Securities in Los Angeles.

To illustrate, individuals may pay $5 \%$ to $10 \%$ for a crossborder money transfer via Western Union or MoneyGram. Further, merchants may pay $3 \%$ or more of the item's price to accept the payments via credit card or PayPal. The fee is less than $1 \%$ using Bitcoin. Also, Bitcoin could be used to make micropayments for as little as a penny, which might have implications for smaller transactions (such as purchasing digital content online).

In addition, roughly half of the world's adults -2 billion according to a 2014 World Bank white paper-do not have access to bank accounts. Bitcoin offers such people a way to participate in the noncash economy.

\section{PORTFOLIO IMPLICATIONS}

Many investors are keen to learn how to value Bitcoin and incorporate it into portfolios. To gain exposure to Bitcoin, they can buy and sell the cryptocurrency on a trading platform. They can also buy a publicly traded instrument, such as the Bitcoin Investment Trust, through any broker. Plans are also in the works to introduce a Bitcoin exchange-traded fund (ETF). (In September, ARK Investment Management announced that its ARK Web x.0 ETF would invest in shares of the Bitcoin Investment Trust.) Additionally, investors can invest in many companies that have emerged as businesses based on Bitcoin and blockchain technology, either directly or through venture capital funds.

"Bitcoin is a financial instrument the likes of which we have never seen. It's not quite equity, it's not quite commodity, so it's very hard to value it," says Luria. "An approach to valuing it involves thinking of it as a packet that can carry value and is in limited supply." (Notably, however, the US Commodity Futures Trading Commission recently defined Bitcoin and other virtual currencies as "commodities.")

But valuation is getting easier.

NYSE has a Bitcoin index. Market data are available from the exchanges. Bloomberg, Thomson Reuters, and CoinDesk carry quotes and news. Pricing and volatility calculations are available from BitMEX in Hong Kong and TradeBlock in New York.

In addition, academic research is being undertaken to figure out the correlations between Bitcoin and such assets as gold, oil, and the S\&P 500 Index as well as what a portfolio's efficiency looks like in a digital currency world.

\section{HEADWINDS AND TAILWINDS}

Some material structural flaws in the economics and processes around Bitcoin mining are not properly understood by Bitcoin evangelists or the broader public, according to John Dwyer, a senior analyst at Celent. This has implications for broader adoption into mainstream finance.

Miners are incentivized to validate transactions by earning new Bitcoin, Dwyer explains. But the incentive mechanism halves about every four years based on the deterministic nature of the incentive and how it is mathematically forecasted and calculated within the protocol. If the Bitcoin price does not increase to offset the decreasing incentive mechanism, revenue to miners will fall. This limitation is significant because miners provide security to the network, and they may not be appropriately compensated for performing that function. In addition, mining is extremely expensive because it consumes enormous amounts of electricity.

"Ultimately, the industry business model of mining cannot be anything other than marginally profitable in the long run and therefore is not viable given the risk inherent in the business," says Dwyer.

He also warns that the Bitcoin network is vulnerable to a "51\% attack" (currency takeover), in which a bad actor could gain control of the network's mining capacity and the blockchain. Theoretically, the incentive mechanism was created so it would be too expensive for anyone to do that; however, the declining incentive to mine provides a clear path toward centralization of the mining function such that only a few mining pools actually control the vast majority of the network. The fact that miners are pseudonymous raises concerns from a governance perspective.

Finally, Bitcoin is a decentralized autonomous organization, like the internet, which means nobody controls it, and it is difficult to change protocol.

Still, bullish observers believe that Bitcoin, blockchain, and distributed ledger technology will be the financial operating system of the future, and it could be the basis for a business model that displaces some existing enterprises. Early investors in next-generation companies may have the most to gain from the expected rapid pace of innovation and value creation over the next decade.

"Will Blockchain Change Wall Street? The More Things Change, the More They Stay the Same," Market Integrity Insights (17 September 2015) [blogs.cfainstitute.org/marketintegrity]

"Warren Buffett Is Wrong: The Bitcoin Proof," Enterprising Investor (14 January 2015) [blogs.cfainstitute.org/investor]
Sherree DeCovny is a freelance journalist specializing in finance and technology. 